
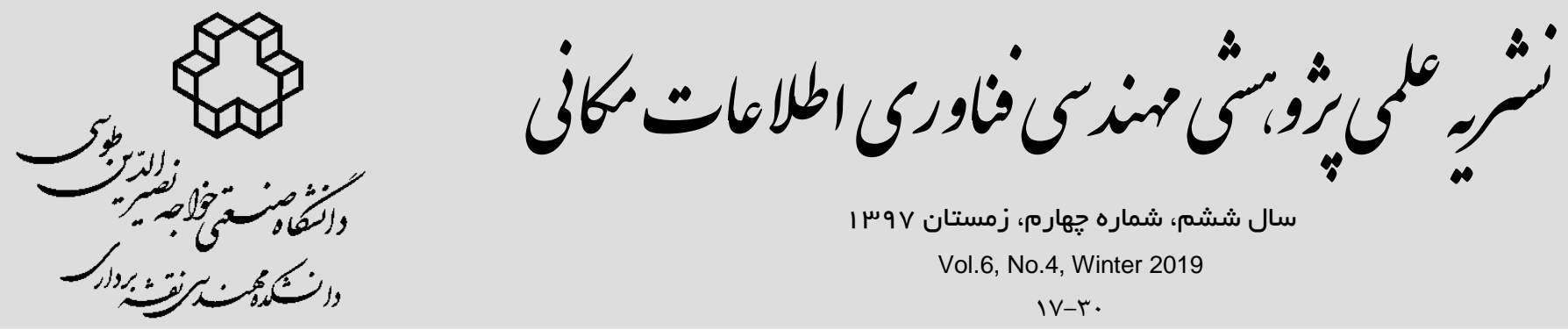

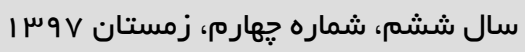

Vol.6, No.4, Winter 2019

IV-r.

تخمين شدت بيمارى زنَ برى تندم با استفاده از روشهاى كدكذارى طيف بازتابندكى

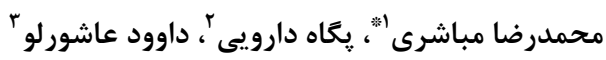 \\ ا - - استاد مهندسى سنجش ازدور، آزمايشكاه سنجشازدور، موسسه آموزش عالى خاوران

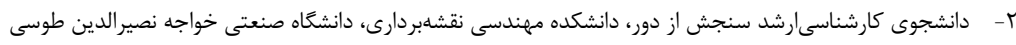

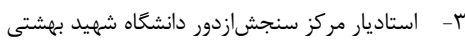

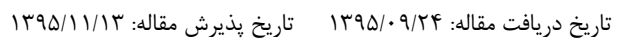

جكيده

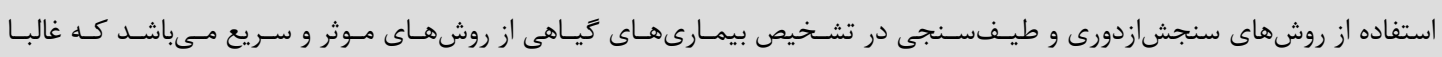

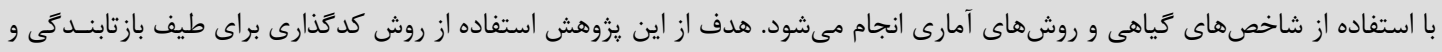

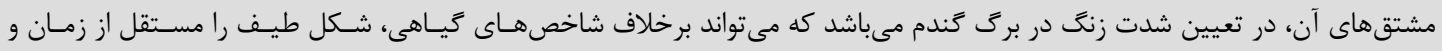

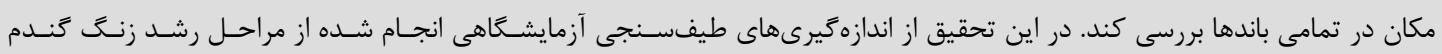

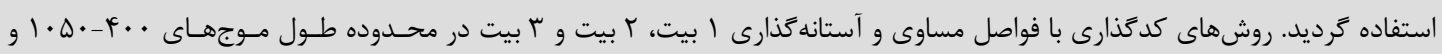

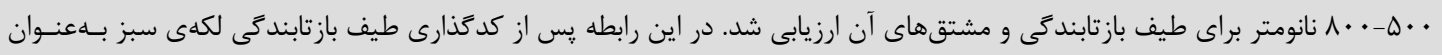

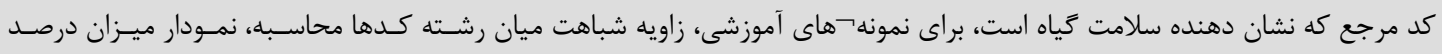

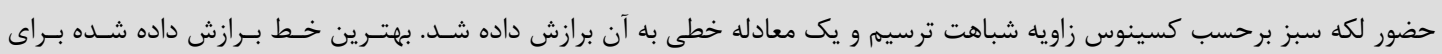

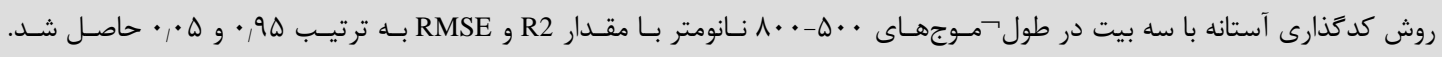

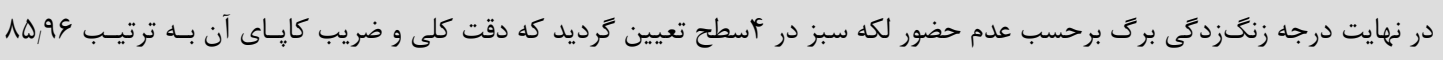
درصد و ا مر • مى باشد.

كليد وازهها: بازتابندگى، كدگذارى، زاويه شباهت، زنگ گندم، مشتق

* نويسنده مكاتبه كننده: مشهل، شهر ك غرب، بزركراه امامعلى، بلوار شهيد رفيعى، خيابان شهيد برادران حسينى Ir ا، موسسه آموزش عالى خاوران

تلفن: 


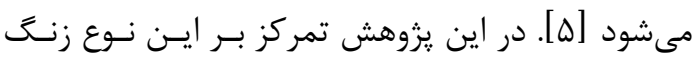

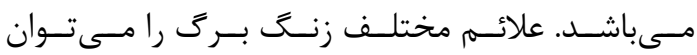
بهطور همزمان در قطعات مختلف از يك برك مشـاهده

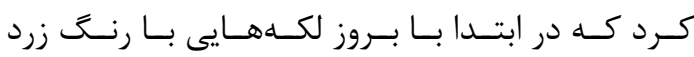
نمايان مىشوند، سيس با ٍِيشـرفت بيمـارى در مراحـل

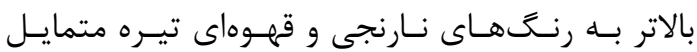

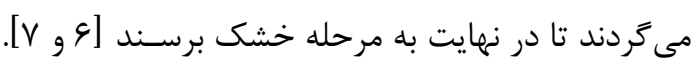

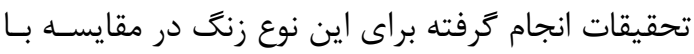

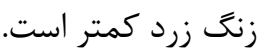

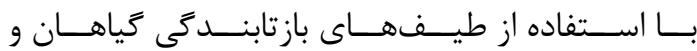

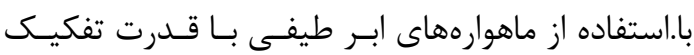

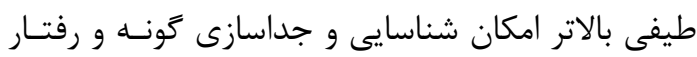

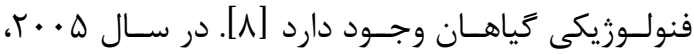
فرانك و همكاران بلمنظــور مقايسـه عملكـرد سـنجنده

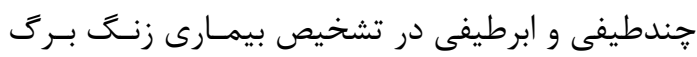

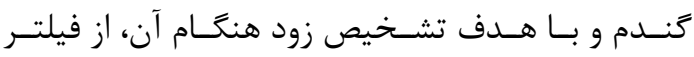

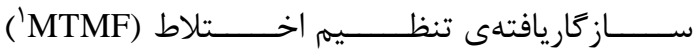

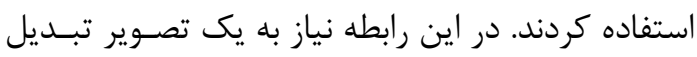

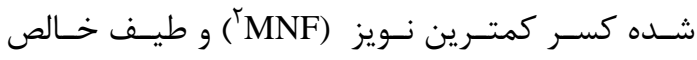

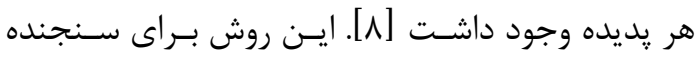

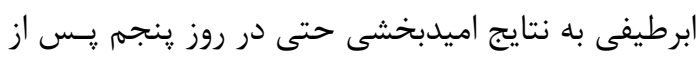

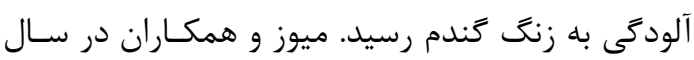

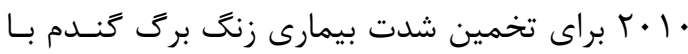

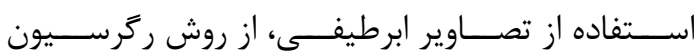

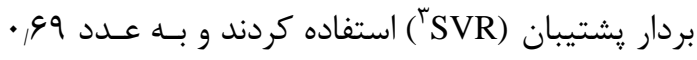

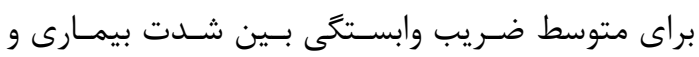

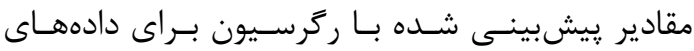

آزمون رسيدند [9].

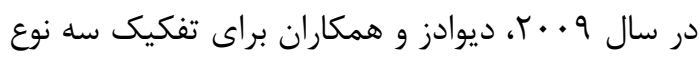
زنگ كندم از • ل1 شاخص طيفى استفاده نمودند. نتـايج آنها نشان داد كه شاخص منحصر به فردى بر براى تمايز

\footnotetext{
${ }^{1}$ Mixture Tuned Matched Filtering

${ }^{2}$ Minimum Noise Fraction

${ }^{3}$ Support Vector Regression
}

| - 1- (- مقدمه

تلاش براى تشخيص و مقابلـهـ بـا بيمـارىهــاى كيـاهى

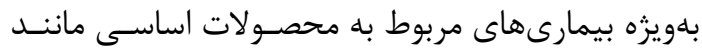

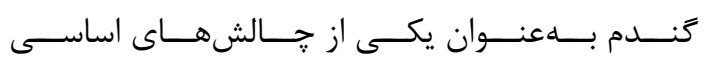

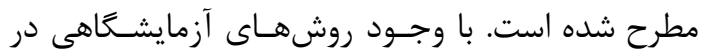

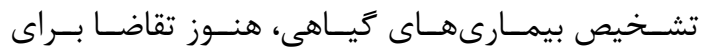

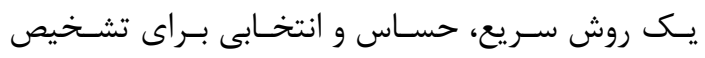

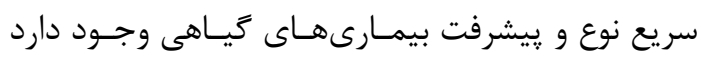

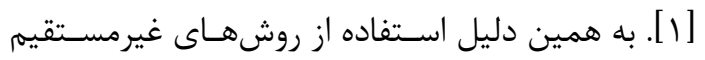

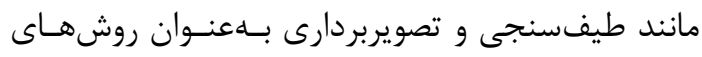

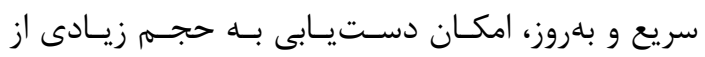

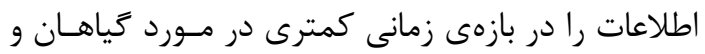
بيمارى هاى آنها فراهم مى كند.

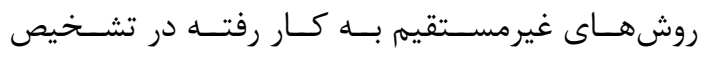
بيمارىهاى كياهى با استفاده از طيفسنجى را مىتوان

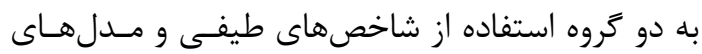

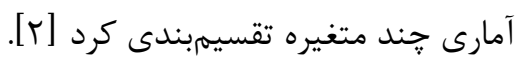

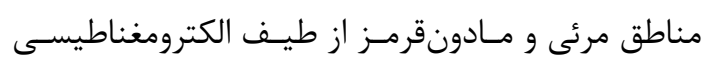

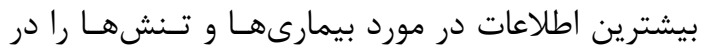

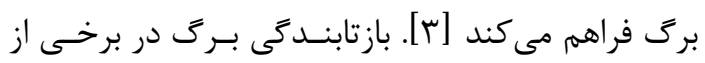

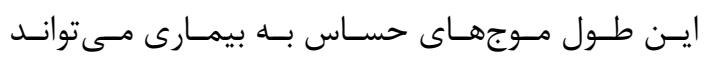

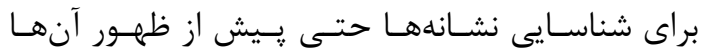

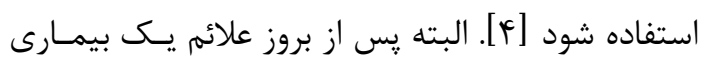

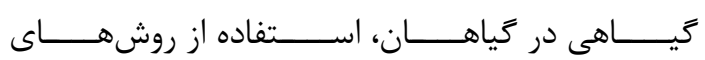
تشخيص بيمارى قابل انجام است.

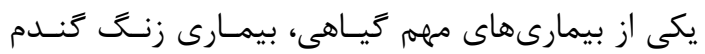

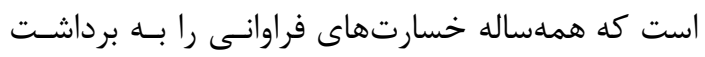

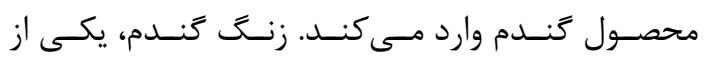

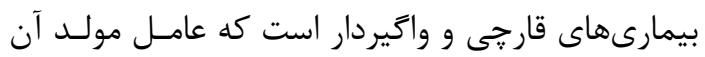

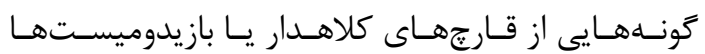

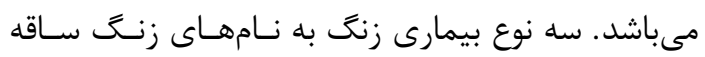

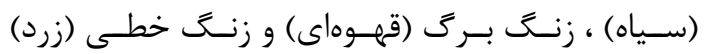

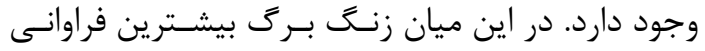

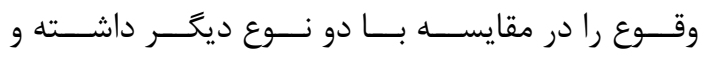
بـهاطــور خشـمخيرى باعـث كـاهش عملكـرد محصـول 
حالى است كه روشهاى ركرسيون آموزشى مىتوانند از

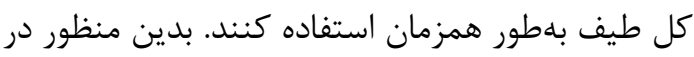
سال 19 •r عاشورلو و همكاران از سـه روش ركرسـيون حداقل مربعات جزئى، مدل ركرسيون بردار يشـتيبان و و

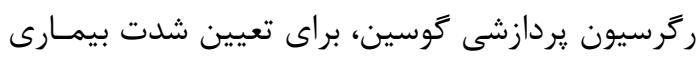

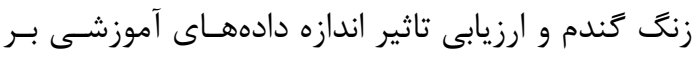

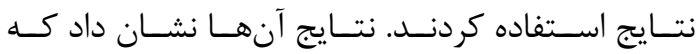

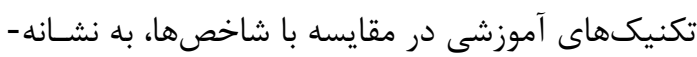

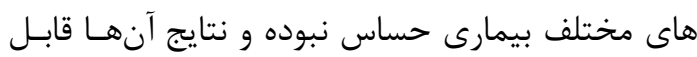

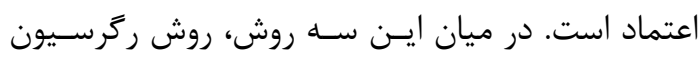

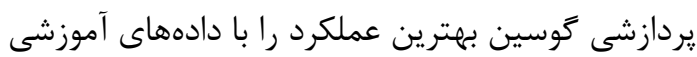

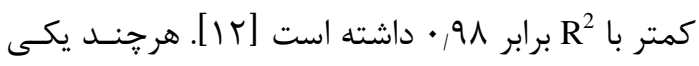

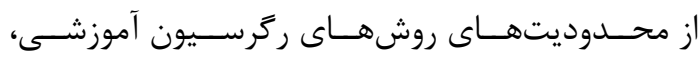
حساس بودن به اندازه نمونههاى آموزشى است.

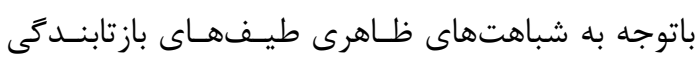

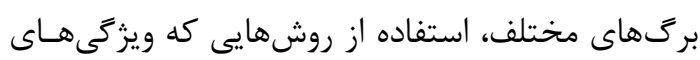

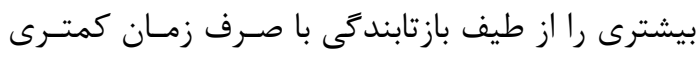

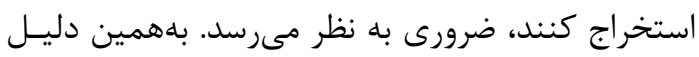

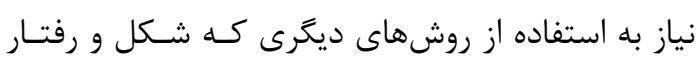

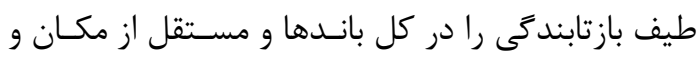
زمان در نظر مى گيـرد، احسـاس مسىشـود. اسـتفاده از

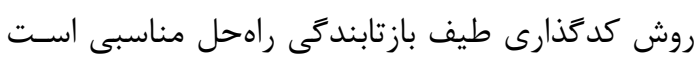

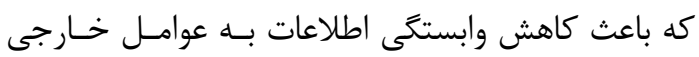

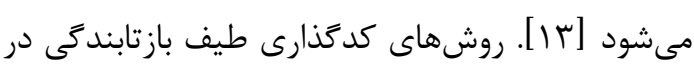

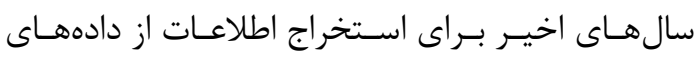

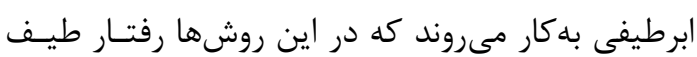

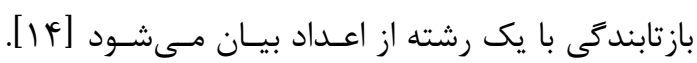

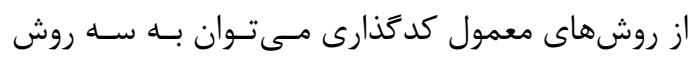

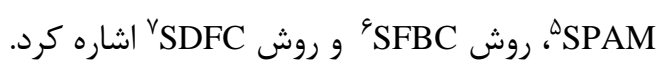

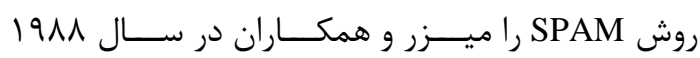
با تركيب روش آستانهكَارى با مقدار ميـانكَين مقـادير

\footnotetext{
${ }^{5}$ Spectral Analysis Manager

${ }^{6}$ Spectral Feature-based Binary Coding

${ }^{7}$ Spectral Derivative Feature Coding
}

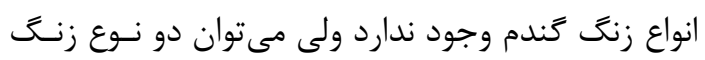

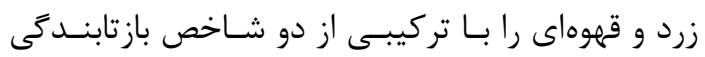

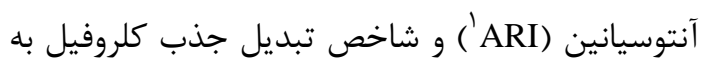

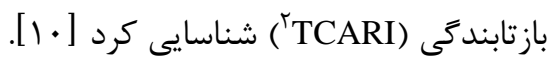

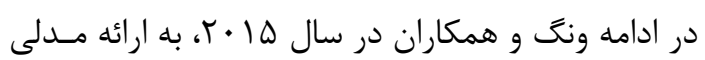

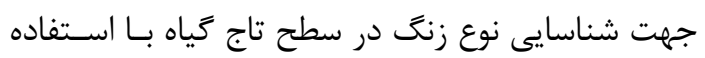

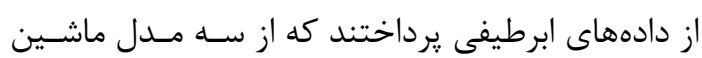

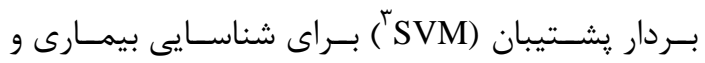

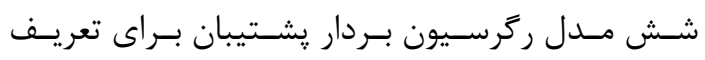

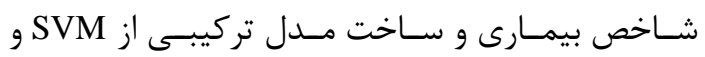

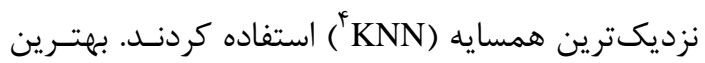

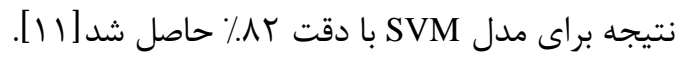
شاخصهاى كياهى و شاخصهاى بيمارى تـا بــهـ امـروز

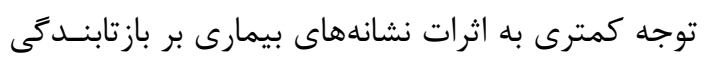

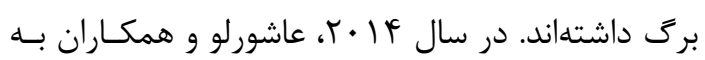

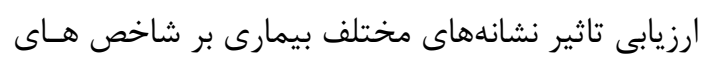

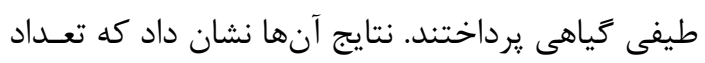

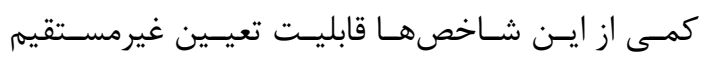

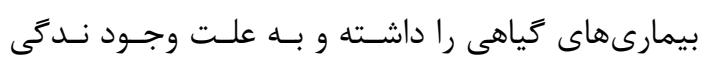

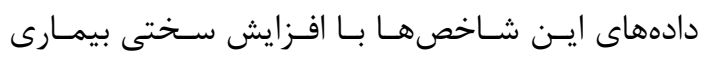

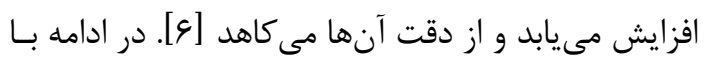

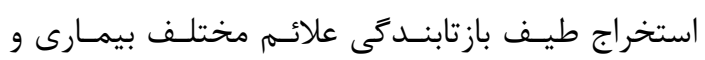

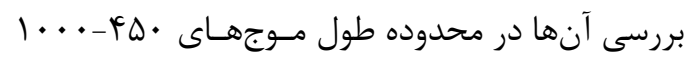

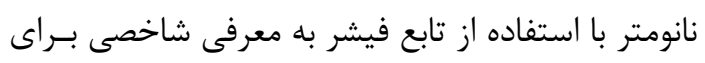

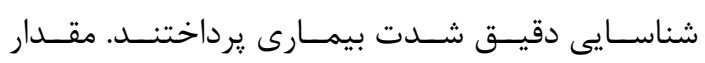

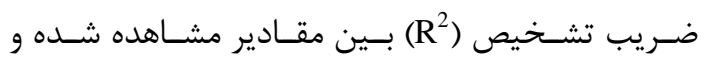

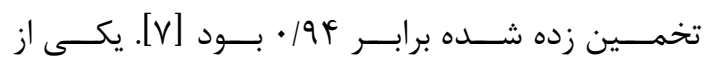

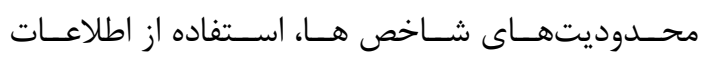

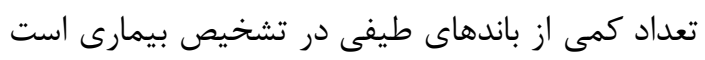

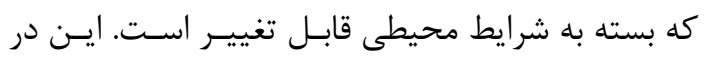

\footnotetext{
${ }^{1}$ Anthocyanin Reflectance Index

${ }^{2}$ Transformed chlorophyll Absorption in Reflectance Index

${ }^{3}$ Support Vector Machine

${ }^{4}$ k-Nearest Neighbors
} 
كد نهايى با تركيب روابط (r و r) با رابطه (؟) بهصورت رابطه (V) (Vاصل مىشود.

$S_{l}^{S F B C}=\left(S_{l}^{a} S_{l}^{b} S_{l}^{M D}\right)$

(V) رابطه

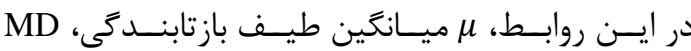

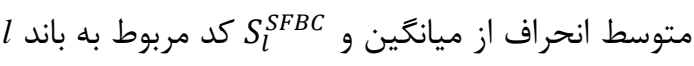

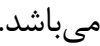
جنَّ و همكاران در سال 9 ×. ז، روش SDFC را بـراى

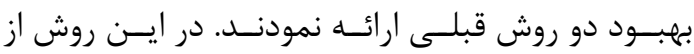

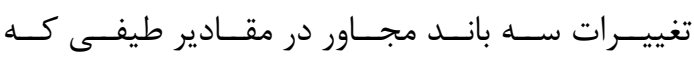
نشـان دهنــدهى تغييـرات در مشــق طيفـى اسـت و و همجنين ميانگين قدرمطلق تفاضل هر باند با باند قبلى دانى (رابطه (9)) استفاده مىشود [IV] $\Delta=\frac{1}{L-1} \sum_{l=2}^{L}\left|s_{l}-s_{l-1}\right|$

رابطه (ر) (ر)

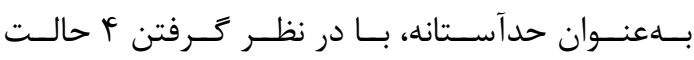

باز تابندگى و اختلاف مقدار باند بعدى از باند قبلى بانســـ

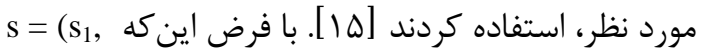
يك امضاى ابرطيفى با L باند باشد:

$$
\begin{aligned}
& \mu=\frac{1}{L} \sum_{i=1}^{l} s_{i} \\
& \text { رابطه (1) } \\
& S_{l}^{a}= \begin{cases}0, & s_{l}<\mu \\
1, & s_{l} \geq \mu\end{cases} \\
& \text { رابطه (T) } 1 \leq L \\
& \text { رابطه (T) }
\end{aligned}
$$

$S_{l}^{b}=\left\{\begin{array}{l}0, s_{l+1}<s_{l-1} \\ 1, s_{l+1} \geq s_{l-1}\end{array}\right.$ $2 \leq l \leq L-1$

$S_{l}^{S P A M}=\left(S_{l}^{a} S_{l}^{b}\right)$

(ابطه (c)

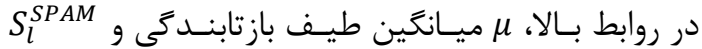
كد مربوط به باند ا مى باشد.

روش SFBC ، توسط كيان و همكاران در سال 1999 با با

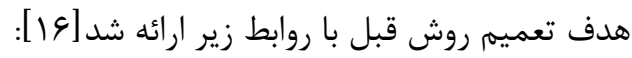

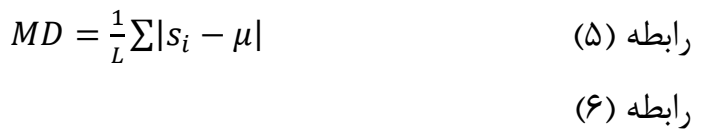

$S_{l}^{M D}=\left\{\begin{array}{ll}0 & \left|s_{l}-\mu\right|<M D \\ 1 & \left|s_{l}-\mu\right| \geq M D\end{array} \quad 1 \leq l \leq L\right.$

$$
\left|s_{l}-s_{l-1}\right| \leq \Delta,\left|s_{l+1}-s_{l}\right| \leq \Delta
$$

$S_{l}^{b-S D F C}=\left\{\begin{array}{l}0 \text { or } 00 \\ 1 \text { or } 01 \\ 2 \text { or } 10 \\ 3 \text { or } 1\end{array}\right.$

$\left|s_{l}-s_{l-1}\right| \leq \Delta,\left|s_{l+1}-s_{l}\right|>\Delta$ or $\left|s_{l}-s_{l-1}\right|>\Delta,\left|s_{l+1}-s_{l}\right| \leq \Delta$

$$
\begin{aligned}
& s_{l}-s_{l-1}<\Delta, s_{l+1}-s_{l}<\Delta \text { or } s_{l}-s_{l-1}>\Delta, s_{l+1}-s_{l}>\Delta \\
& s_{l}-s_{l-1}<\Delta, s_{l+1}-s_{l}>\Delta \text { or } s_{l}-s_{l-1}>\Delta, s_{l+1}-s_{l}<\Delta
\end{aligned}
$$

$S_{l}^{S D F C}=\left(S_{l}^{a} S_{l}^{b-S D F C}\right)$

رابطه (•)

در سنجش از دور ابرطيفى، براى اسـتخراج اطلاعـات از

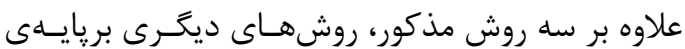
طيف بازتابندىى، از روشهاى تحليل مشتق طيفى نيـز

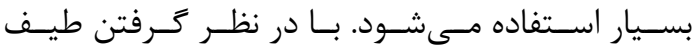

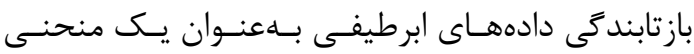

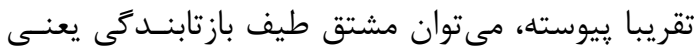

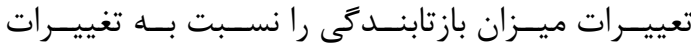

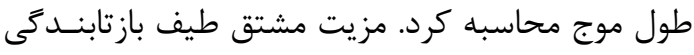

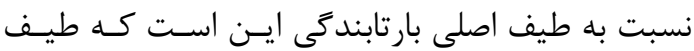

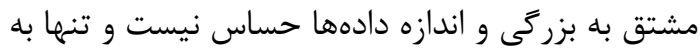

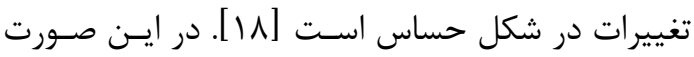

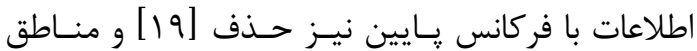

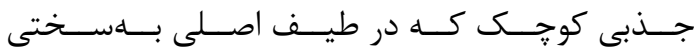

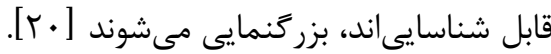

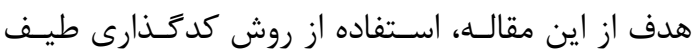

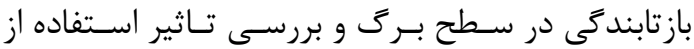

مشتق گيرى از طيف باز تابنـدكى در مراتـب بـالاتر نيـز

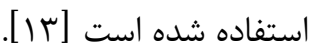

براى مقايسه كدهاى مرجــع بــا كـدهاى مجهــول از دو

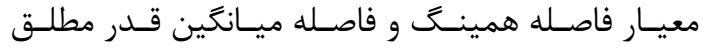

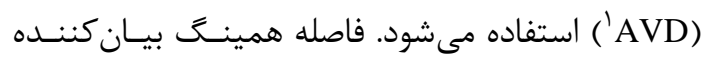

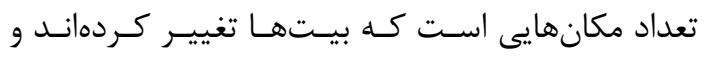
درواقع بيان كننده ميزان تفاوتهاست. فاصـله ميـانكين

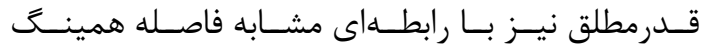
محاسبه مى گردد با اين تفاوت كـه در فاصـله همينــ كدها به صورت دودويى هستند ولى در فاصله ميـانگين قدر مطلق، كدها اعداد حسابى از صفر تا يكى كمتــ از

${ }^{1}$ Absolute Value Distance 


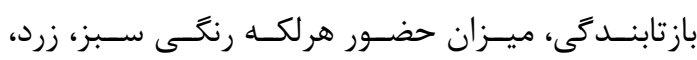

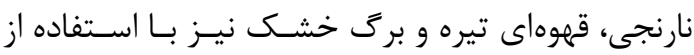

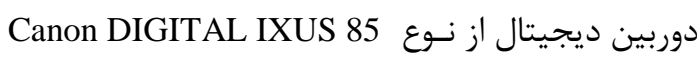

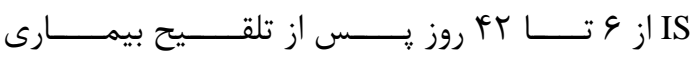

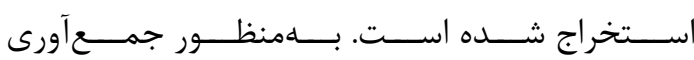
نمونههاى كافى، كشت كندم و آلودهسازى آن دو مرتبه

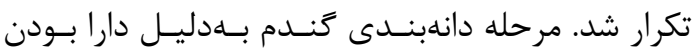

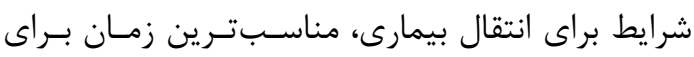

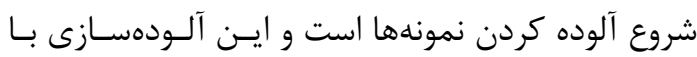

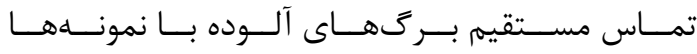

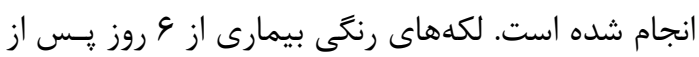

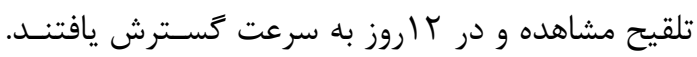

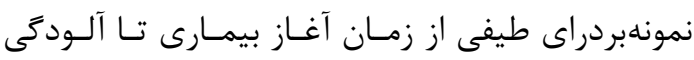

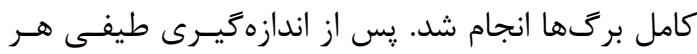

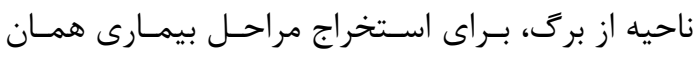

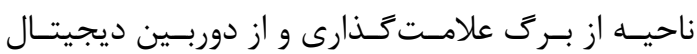

$$
\text { - - تصى مراحل زير استفاده گرديد: }
$$

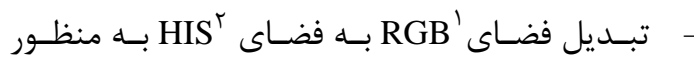

$$
\text { حذف اثر تغييرات احتمالى شدت نور }
$$

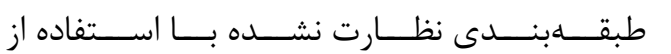

روش K-means

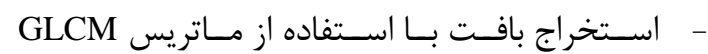

بامنظور تعيين دقيق مرز نواحى بيمار

- مبقهبندى نظارتشده با روش حداكثر احتمال

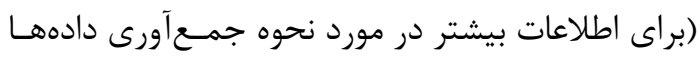
به مراجع r، צ، V و rاى اط رجوع شود.)

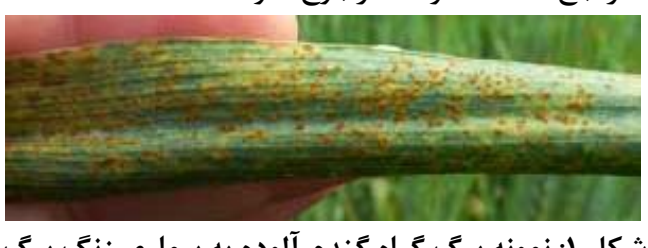

[r)]

\footnotetext{
${ }^{1}$ Red, Green, Blue

${ }^{2}$ Hue, Saturation, Intensity
}

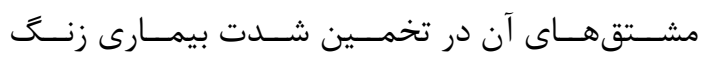
برى گندم مى باشد. در ابتدا طيف بازتابندگى لكه سـبز

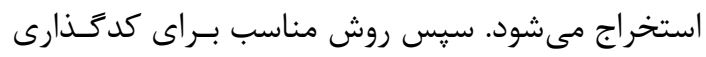
انتخاب و كد مرجع لكه سبز كه نشان دهنـده سـلامت

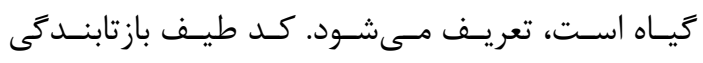
نمونههاى آموزشى به همان روش تهيه و زاويه شـبـاهت بين آنها و كدهاى مرجـع محاسـبه مـى آشـود. يـس از تشكيل مدل، درجهبندى زنــ گَنـدم براسـاس ميـزان وجود لكه سبز انجام مىشود.

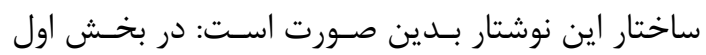

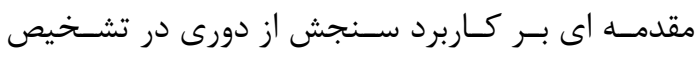

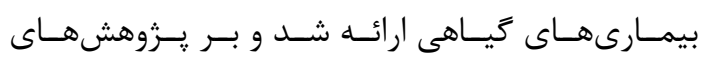
انجام گرفته در زمينه زنت گندم، روشهاى كدگذارى و

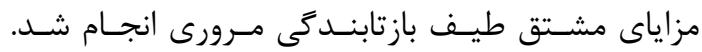

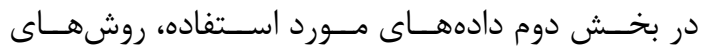
كدگذارى مورد استفاده و روندكار توضيح داده مى دودى دون. در بخش سوم نتايج و در بخش آخر نتيجه كيـرى كلى دورى بيان مى شود.

\section{r - دادهها و روشها}

در ايـن بخـش بــه معرفـى دادههــاى اسـتفاده شـده و روشهاى كد گذارى مورد استفاده يرداخته مى بـود. r-1 - - - 1ادههاى مورد استفاده دادههــاى مــورد اسـتفاده در ايـن پــروهش نمونـهـهـاى طيفسنجى شده توسط مباشـرى و همكـاران (T/ • (Y)

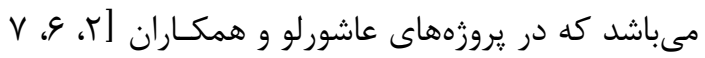
و r I ] توضيح داده شدهاسـت. در ايـن كـار ميـدانى، از دو نوع برى گَياه گَندم بولانى و روشن كه حسـاس بـهـ بيمارى زنگ برى هستند و بهصورت گسترده در ايسران كشت مىشود، استفاده شد و در طولموجهاى • له تـا

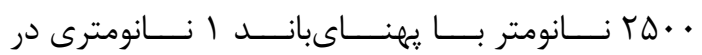
مراحـلـ مختلـف بيمـارى در شــرايط كنتــرل شــده بــا

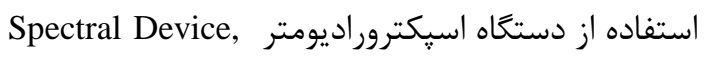
(Analytical Boulder,

$\mathrm{CO}$,

USA) 


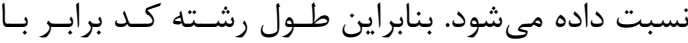

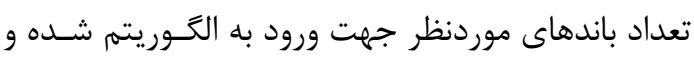

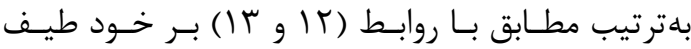
بازتابندكى و مشتقهاى آن اعمال مسىشـود. در مرحلـهـ

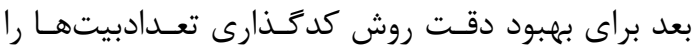
افزايش داده و الكوريتم تكرار مىشـود. در ايسن صـورت

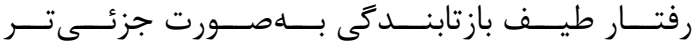
بررسى مسىشـود. در روش ابيـت (روابـط ها و و (1) و و

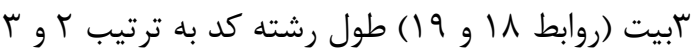

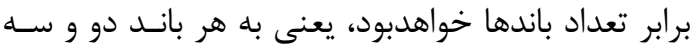

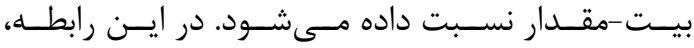
بازتابندكى عددى بين صفر و يك است. ولى مشـتقات

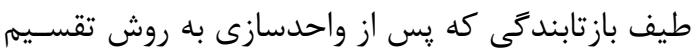
هر عدد بر قدرمطلق بزر كترين مقدار است، بـين اعـداد

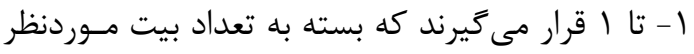
به rا، أ و يا م فاصله تقسيم مىشوند. كد نهايى هربانـد

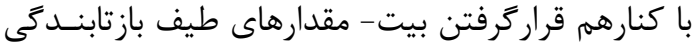

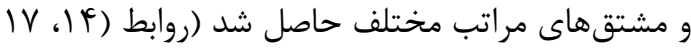

( ( $r \cdot g$

$$
\begin{aligned}
& S_{l}^{R_{-} 1}= \begin{cases}0 & \text { if } s_{l} \leq 0.5 \\
1 & \text { if } s_{l}>0.5\end{cases} \\
& S_{l}^{R^{\prime}{ }_{-}}= \begin{cases}0 & \text { if } s_{l}^{\prime} \leq 0 \\
1 & \text { if } s_{l}^{\prime}>0\end{cases}
\end{aligned}
$$

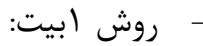

$$
\begin{aligned}
& S_{l}^{R_{-} 2}=\left\{\begin{array}{lll}
00 & \text { if } & 0 \leq s_{l}<0.25 \\
01 & \text { if } & 0.25 \leq s_{l}<0.5 \\
10 & \text { if } & 0.5 \leq s_{l}<0.75 \\
11 & \text { if } & 0.75 \leq s_{l} \leq 1
\end{array}\right. \\
& S_{l}^{R_{2} 2}=\left\{\begin{array}{lll}
00 & \text { if } & -1 \leq s_{l}^{\prime}<-0.5 \\
01 & \text { if } & -0.5 \leq s_{l}^{\prime}<0 \\
10 & \text { if } & 0 \leq s_{l}^{\prime}<0.5 \\
11 & \text { if } & 0.5 \leq s_{l}^{\prime} \leq 1
\end{array} \quad\right. \text { (|\&) } \\
& S_{l}^{R R^{\prime}}=\left(S_{l}^{R_{-}{ }^{2}} S_{l}^{R^{\prime}{ }_{-}{ }^{2}}\right) \\
& \text { رابطه (IV) }
\end{aligned}
$$

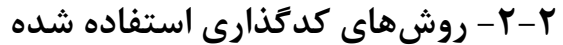
روشهايى كه براى كدگذارى طيف بازتابندگى لكه سبز استفاده شد، به شرح زير است:

روش اول: كدكذارى با فواصل مساوى (EIC')

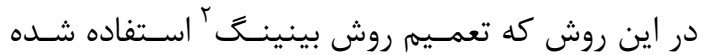

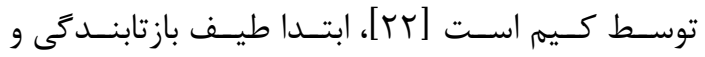

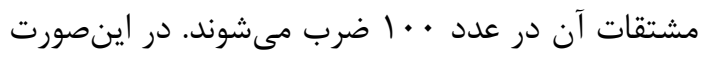

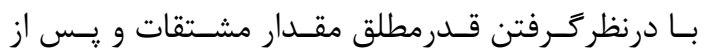

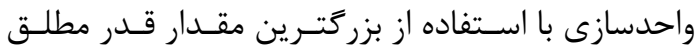

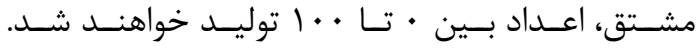
سيس اين فاصله به له قسمت مسـاوى تقسـيم كرديـد.

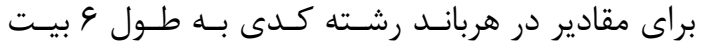

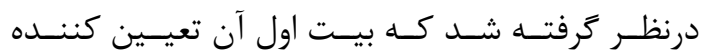
علامت است (اكر مثبت باشـــ ا و درغيـر ايـن صـورت

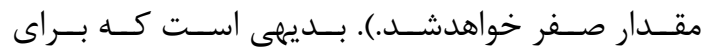

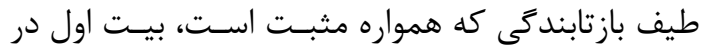

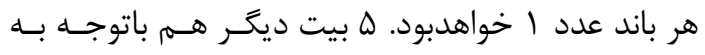

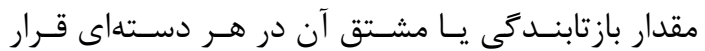

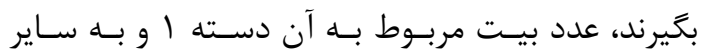
بيتها صفر اختصاص داده خواهدشد.

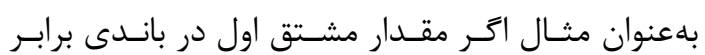

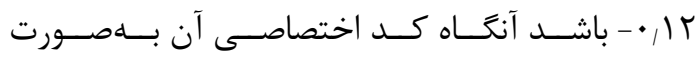
جدول (1) تعريف مىشود:

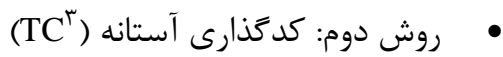

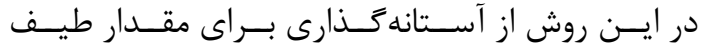

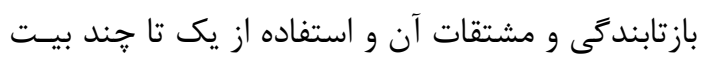

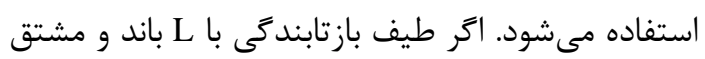
آن به ترتيب مطابق روابط زير باشد:

$$
\begin{aligned}
& \mathrm{s}=\left\{\mathrm{s}_{1}, \mathrm{~s}_{2}, \mathrm{~s}_{3}, \ldots, \mathrm{s}_{\mathrm{L}}\right\} \\
& \text { رابطه (1) } \\
& s^{\prime}=\left\{s_{1}^{\prime}, s_{2}^{\prime}, s_{3}^{\prime}, \ldots, s_{L}^{\prime}\right\} \\
& \text { در روش ا بيـت بــه هـــر بانــد يـك بيـت-مقـــدار }
\end{aligned}
$$

\footnotetext{
${ }^{1}$ Equal Intervals Coding

${ }^{2}$ Binnig

${ }^{3}$ Threshold Coding
} 


\section{r- اجراى كدكذارى و ارزيابى}

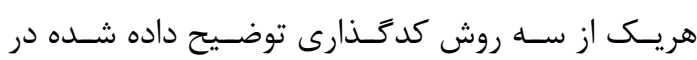

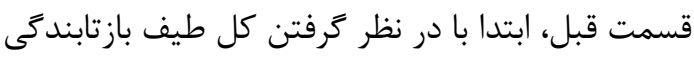

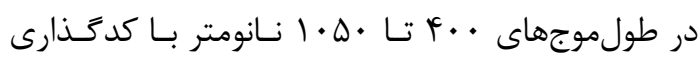

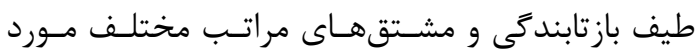

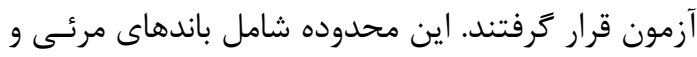

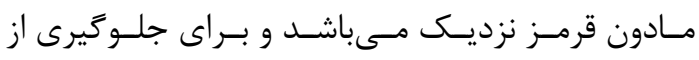

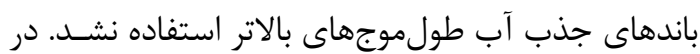
مر حله بعد به علت وجود برخى نواحى طيفـى بـا رفتـار

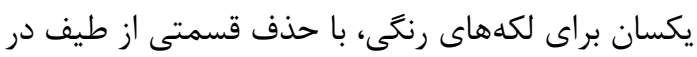

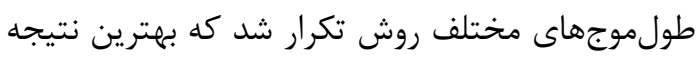

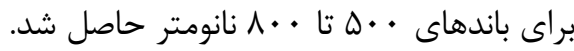

$$
S_{l}^{R_{3}}=\left\{\begin{array}{clc}
000 & \text { if } & 0 \leq s_{l}<0.125 \\
001 & \text { if } & 0.125 \leq s_{l}<0.25 \\
010 & \text { if } & 0.25 \leq s_{l}<0.375 \\
100 & \text { if } & 0.375 \leq s_{l}<0.5 \\
011 & \text { if } & 0.5 \leq s_{l}<0.625 \\
101 & \text { if } & 0.625 \leq s_{l}<0.75 \\
110 & \text { if } & 0.75 \leq s_{l}<0.875 \\
111 & \text { if } & 0.875 \leq s_{l} \leq 1
\end{array}\right.
$$$$
S_{l}^{R_{3}}=\left\{\begin{array}{clc}
000 & \text { if } & -1 \leq s_{l}^{\prime}<-0.75 \\
001 & \text { if } & -0.75 \leq s_{l}^{\prime}<-0.5 \\
010 & \text { if } & -0.5 \leq s_{l}^{\prime}<-0.25 \\
100 & \text { if } & -0.25 \leq s_{l}^{\prime}<0 \\
011 & \text { if } & 0 \leq s_{l}^{\prime}<0.25 \\
101 & \text { if } & 0.25 \leq s_{l}^{\prime}<0.5 \\
110 & \text { if } & 0.5 \leq s_{l}^{\prime}<0.75 \\
111 & \text { if } & 0.75 \leq s_{l}^{\prime} \leq 1
\end{array}\right.
$$

رابطه (r) ( ) ( )

\begin{tabular}{|c|c|c|c|c|c|c|}
\hline+ or - & $0 \leq$ value $<20$ & $20 \leq$ value $<40$ & $40 \leq$ value $<60$ & $60 \leq$ value $<80$ & $80 \leq$ value $\leq 100$ & مقادير \\
\hline • & 1 & - & - & - & - & كد باينرى \\
\hline
\end{tabular}

جدول ا: نمونه اختصاص كد به مقادير در محدودههاى مختلف

لكه سبز است، از كسينوس زاويه شباهت استفاده شـد.

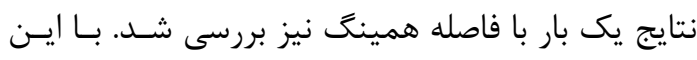

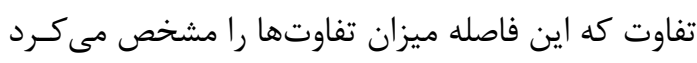

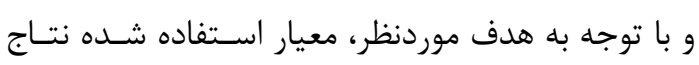
بهترى را ارائه نمود.

$$
\mathrm{PG}=\mathrm{a} \times \mathrm{CS}+\mathrm{b}
$$

براى ارزيابى مدل، درصد حضور لكه سبز با معادله خط بدست آمده تخمين زده شد و وبا مقدار واقعى اسـتخراج

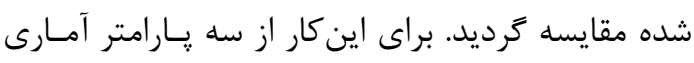

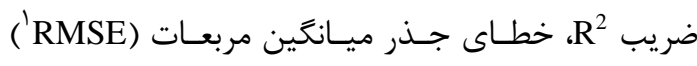

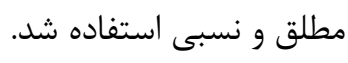

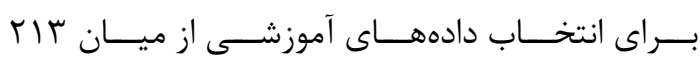

\footnotetext{
${ }^{1}$ Root Mean Square Error
}

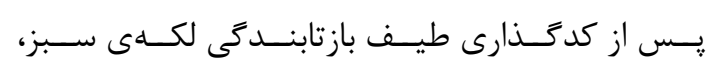

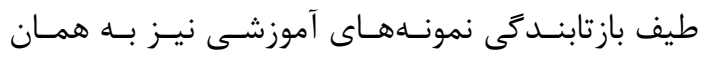

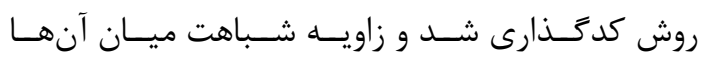

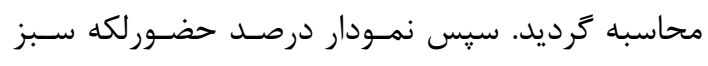

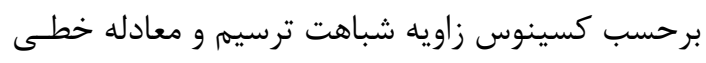

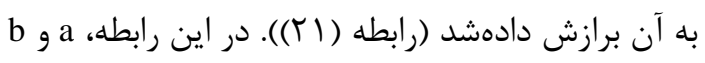

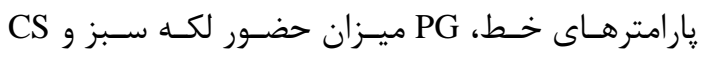

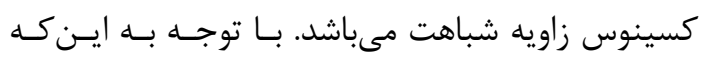

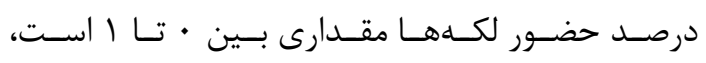

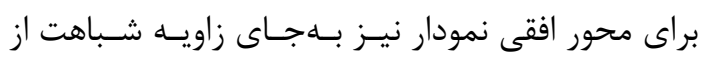

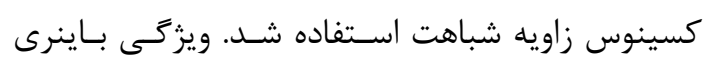

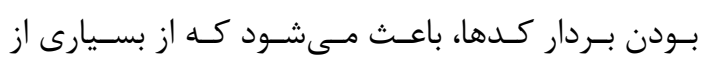

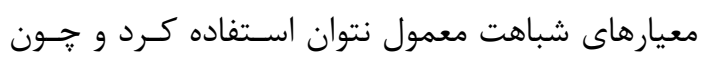
هدف برقرارى رابطه ميان زاويه شباهت و كســر حضــور 
طول موج هاى مورد اسـتفاده دارد. مقايسـهـ كلـى بــين

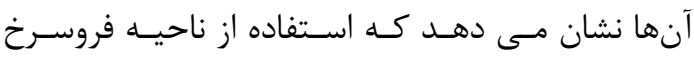
نزديك و حذف باند آبى از ناحيه مرئى در بهبـود نتـايج

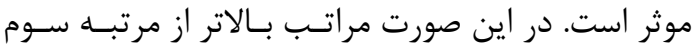

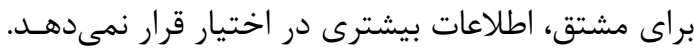

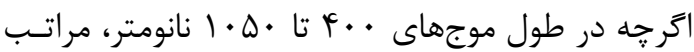

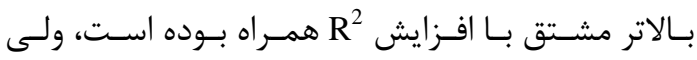
RMSE

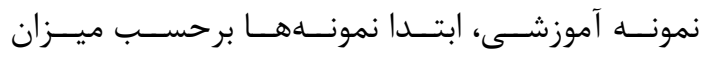
حضورلكه سبز مرتب شد. سيس از هر دو نمونسه، يكى آنس براى آزمون و ديكرى براى آموزش انتخاب شدند.

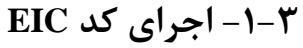
كد EIC با در نظر حـرفتن طيـف بازتابنـدكى و مراتـب

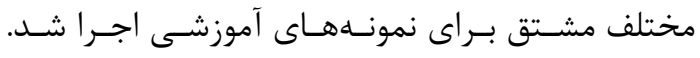

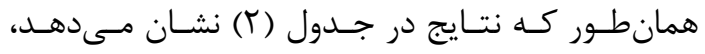

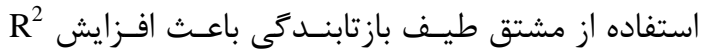

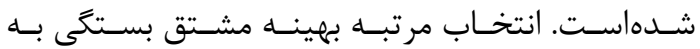

جدول r: نتايج اجراى كد EIC

\begin{tabular}{|c|c|c|c|c|c|c|c|c|c|c|}
\hline \multicolumn{5}{|c|}{ 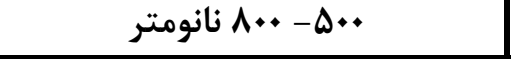 } & \multicolumn{5}{|c|}{ 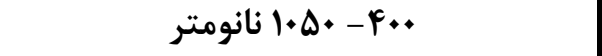 } & \multirow[b]{2}{*}{ طيف هاى استفاده شده } \\
\hline نســـــــ & RMSE & $\mathbf{R}^{2}$ & b & a & 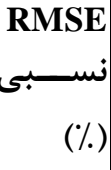 & RMSE & $\mathbf{R}^{2}$ & b & a & \\
\hline $1 \% / 8 \Lambda$ & $.1 \cdot 9$ & $\cdot / \mathrm{A \Lambda}$ & $-1 / T Y$ & $r / 1 Y$ & r & .111 & $\cdot / V F$ & $-r / T q$ & $\mu / \wedge$ & باز تابندىى \\
\hline $11 / \%$ & $\cdot 1 \cdot \Delta$ & .191 & $-1 / 99$ & $r / 9)$ & $\mid V / 19$ & $\cdot 1 \cdot \wedge$ & $\cdot / \wedge \Delta$ & $-r / r \Delta$ & $r / r q$ & بازتابندىى و مشتق اول \\
\hline $1 \cdot 19$ & $\cdot 1 \cdot 0$ & .194 & $-4 / 1 Q$ & $r / r q$ & $\mid F / G V$ & $\cdot / \cdot \mathrm{v}$ & $\cdot 119$ & $-r|\omega|$ & $\varphi / \wedge 9$ & باز تابندگى و مشتق اول تا دوم \\
\hline 11 & $\cdot 1 \cdot 0$ & $\cdot / 94$ & $-T / T V$ & r/AY & $|r / V|$ & $\cdot 1 \cdot \mathrm{V}$ & .191 & $-r / \Delta \wedge$ & $\Delta / 1 T$ & بازتابندگى و مشتق اول تا سوم \\
\hline $11 / \%$ & $\cdot 1 \cdot \Delta$ & $\cdot 194$ & $-T / \mu \cdot$ & $4 / 1$ & $11 \% / 9$ & $\cdot 1 \cdot \mathrm{v}$ & .191 & $-r / \Delta$ & $\Delta / r \wedge$ & بازتابندگى و مشتق اول تا جهارم \\
\hline $11 / 9$ & $\cdot 1 \cdot 9$ & .194 & $-r / T \xi$ & $r / \mu \wedge$ & $\mid F / F V$ & $\cdot / \cdot \mathrm{V}$ & .194 & $-r / r q$ & $\Delta / r q$ & بازتابندكى و مشتق اول تا ينجمم \\
\hline
\end{tabular}

براى حالت سوم بهترين نتيجه بــراى طـول مــوجهـاى

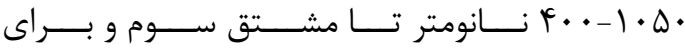

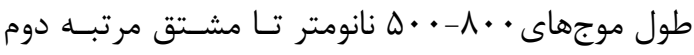

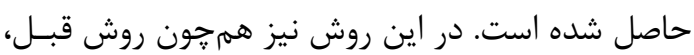

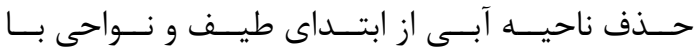

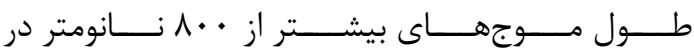
بهبود نتايج موثر است.

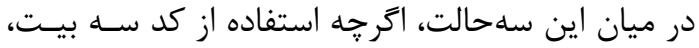

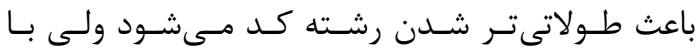

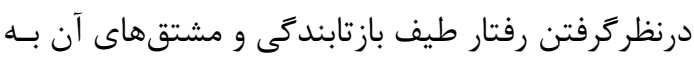

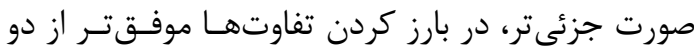

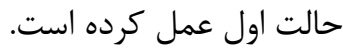

\section{r-r اجراى كد TC} اين كد در سه حالت ابيت، † بيت و آبيـت اجــرا شـد.

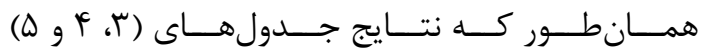
نشان مى دهد، استفاده تنهها از طيف باز تابنـدكى در هـر

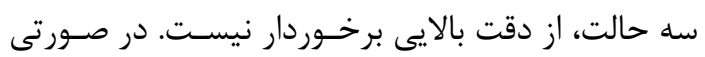

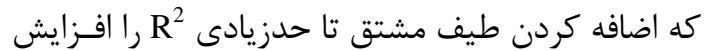
و RMSE نسبى را كاهش داده است. در حالـت ابيـت،

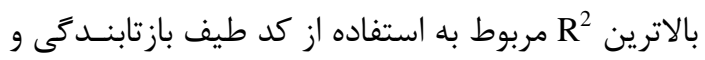

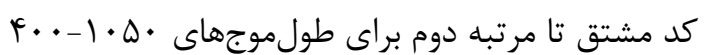

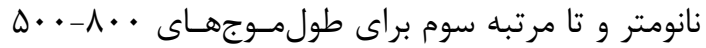

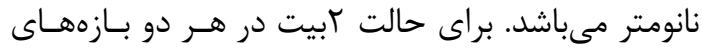

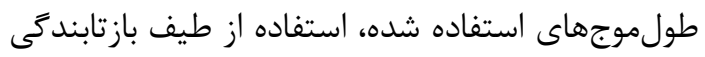

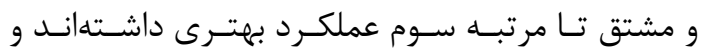


تخمين شدت بيمارى زنكَ برگ كَندم با استفاده از...

محمدرضا مباشرى، يگكاه دارويى، داوود عاشورلو

TC-1 Bit جدول r: نتايج اجراى كد

\begin{tabular}{|c|c|c|c|c|c|c|c|c|c|c|}
\hline \multicolumn{5}{|c|}{ 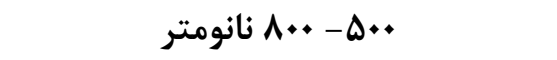 } & \multicolumn{5}{|c|}{ 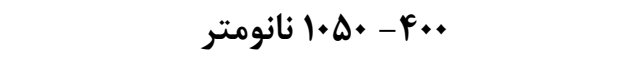 } & \\
\hline $\begin{array}{c}\text { RMSE } \\
\text { نسبىى } \\
\text { (\%) }\end{array}$ & RMSE & $\mathbf{R}^{2}$ & b & $\mathbf{a}$ & \begin{tabular}{|c|} 
RMSE \\
نسبيى \\
$(\%)$
\end{tabular} & RMSE & $\mathbf{R}^{2}$ & b & $\mathbf{a}$ & طيفهاى استفاده شده \\
\hline$r V / Q$ & 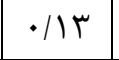 & $\cdot / V 9$ & $-\mid r / \cdot r$ & $\mid r / 91$ & $r V / V$ & 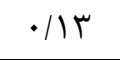 & $\cdot / V 9$ & $-f \Delta / q \uparrow$ & $\varphi \varphi / \Lambda$ & باز تابندگى \\
\hline re/V & • & $\cdot 19 \wedge$ & $-9 / \Delta \Delta$ & 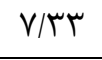 & $10 / \Lambda$ & $\cdot 1 \cdot 1$ & $\cdot / \Lambda \Lambda$ & $-9 /$ & $1 \cdot / 4 q$ & بازتابندگى و مشتق اول \\
\hline Ir & $\cdot 1 \cdot 9$ & .194 & $-r / \Lambda F$ & $\Delta / \cdot \wedge$ & $11 / 9$ & $.1 \cdot 9$ & .194 & $-r / \Delta \Lambda$ & $f / 9 q$ & بازتابندگى و مشتق اول تا دوم \\
\hline $11 / \mu$ & $.1 \cdot 9$ &.$/ 94$ & $-Y / V T$ & $p / \cdot \varphi$ & $1 \pi / 10$ & $.1 \cdot 9$ & .194 & 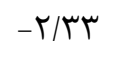 & $r / 9 q$ & بازتابندگى و مشتق اول تا سوم \\
\hline
\end{tabular}

جدول f: جتايج اجراى كد TC-2 Bit

\begin{tabular}{|c|c|c|c|c|c|c|c|c|c|c|}
\hline \multicolumn{5}{|c|}{ 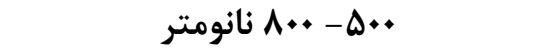 } & \multicolumn{5}{|c|}{ 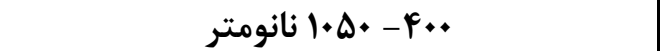 } & \\
\hline $\begin{array}{c}\text { RMSE } \\
\text { نسبى (\%) }\end{array}$ & RMSE & $\mathbf{R}^{2}$ & b & $\mathbf{a}$ & $\begin{array}{c}\text { RMSE } \\
\text { نسبيى (\%) }\end{array}$ & RMSE & $\mathbf{R}^{2}$ & b & $\mathbf{a}$ & طيف هاى استفاده شده \\
\hline $1 N / \cdot \Delta$ & $\cdot 1 \cdot 9$ & $\cdot \mid \Lambda F$ & $-\cdot / \mathrm{VV}$ & $|/ 9|$ & $r \Delta / \Delta$ & .114 & $\cdot / V \Delta$ & $-r / 1 \Delta$ & $r / 9 r$ & باز تابندگى \\
\hline $\mathrm{IV} / \mathrm{A}$ & $\cdot 1 \cdot 9$ & $\cdot \mid \wedge \varphi$ & $-1 / \uparrow \wedge$ & $r / r q$ & $19 / \pi$ & $\cdot 1 \cdot 9$ & $\cdot / \wedge \Delta$ & $-r / \Lambda T$ & r/AD & بازتابندگى و مشتق اول \\
\hline $1 \pi / \Lambda$ & $\cdot 1 \cdot \mathrm{V}$ & .191 & $-1 / \Delta T$ & $r / \Delta \varphi$ & $1 T / 9$ & $\cdot 1 \cdot 9$ & .194 & $-r / \cdot V$ & $\mathrm{~T} / \mathrm{r} \wedge$ & بازتابندگى و مشتق اول تا دوم \\
\hline $11 / 4$ & $\cdot 1 \cdot 9$ & .194 & $-1 / \mathbb{k}$ & $r / \Delta 9$ & $11 / 0$ & $\cdot 1 \cdot 9$ &.$/ 94$ & $-1 / 94$ & $r / \wedge 9$ & بازتابندگى و مشتق اول تا سوم \\
\hline
\end{tabular}

جدول ه: نتايج اجراى كد TC-3 Bit

\begin{tabular}{|c|c|c|c|c|c|c|c|c|c|c|}
\hline \multicolumn{5}{|c|}{ 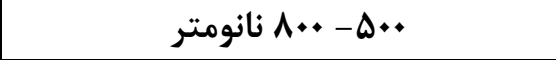 } & \multicolumn{5}{|c|}{ 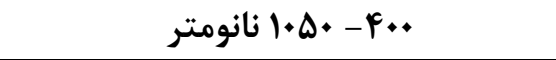 } & \multirow[b]{2}{*}{ طيفهاى استفاده شده } \\
\hline نسبى & RMSE & $\mathbf{R}^{2}$ & b & $\mathbf{a}$ & $\begin{array}{c}\text { RMSE } \\
\text { نسبى } \\
(\%)\end{array}$ & RMSE & $\mathbf{R}^{2}$ & b & $\mathbf{a}$ & \\
\hline$I T / V$ & $\cdot 1 \cdot 9$ & • & $-\cdot / 4 \wedge$ & $1 / \mathbb{\uparrow} \wedge$ & $1 N / \Delta$ & $\cdot 1 \cdot 9$ & $\cdot / \Lambda$ & $-1 / T V$ & $r / l$ & باز تابند \\
\hline $1 \cdot / 11$ & $\cdot 1 \cdot \Delta$ &.$/ 94$ & $-1 / 79$ & $r / r \wedge$ & $\mid r / r$ & $\cdot 1 \cdot V$ & •/AV & $-1 / V 9$ & r/VG & بازتابندگى و مشتق اول \\
\hline $1 \cdot 10$ & $\cdot 1 \cdot \Delta$ & .190 & $-1 / \Delta T$ & r/Ar & $1 T / 0$ & $91 \cdot 9$ & $\cdot 19$ & $-1 / 1$ & 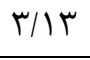 & بازتابندگى و مشتق اول تا دوم \\
\hline $11 / 4$ & $\cdot 1 \cdot 9$ & .194 & $-1 / \Delta \varphi$ & $r / \cdot r$ & $1 T / K$ & $\cdot 1 \cdot 9$ & .191 & $-1 / V F$ & $r / r \Delta$ & بازتابندگى و مشتق اول تا سوم \\
\hline
\end{tabular}

عمودى نيز به ترتيب ميزان حضور لكـهـ سـبز مشـاهده

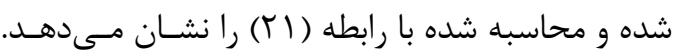

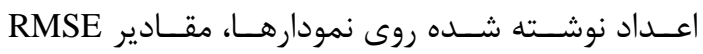
مطلق مىباشند. r-r- تجزيه و تحليل نتايج

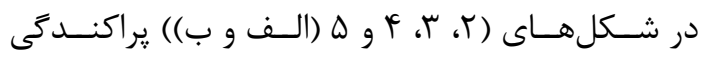

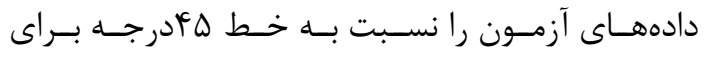

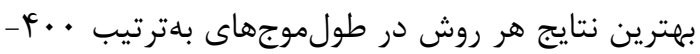

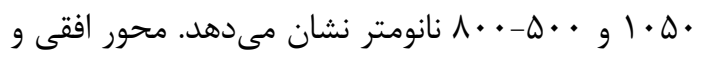



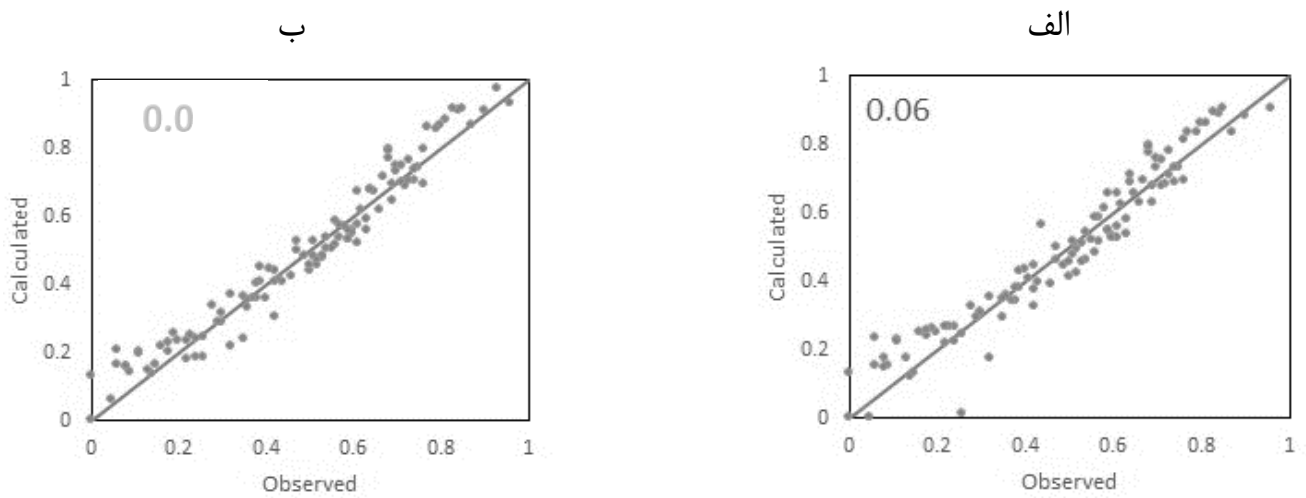

شكل r: نمودار ميزان حضور لكه سبز محاسبه شده بر حسب ميزان مشاهده شده با استفاده از روش EIC

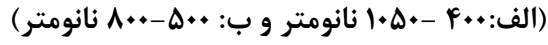

ب

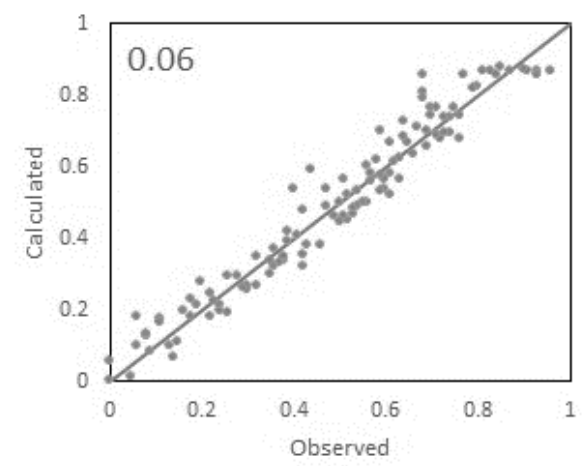

الف

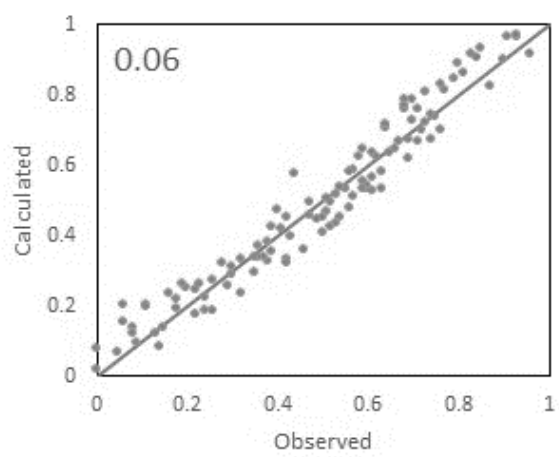

شكل r: نمودار ميزان حضور لكه سبز محاسبه شده بر حسب ميزان مشاهده شده با استفاده از روش TC-1 Bit

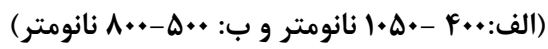
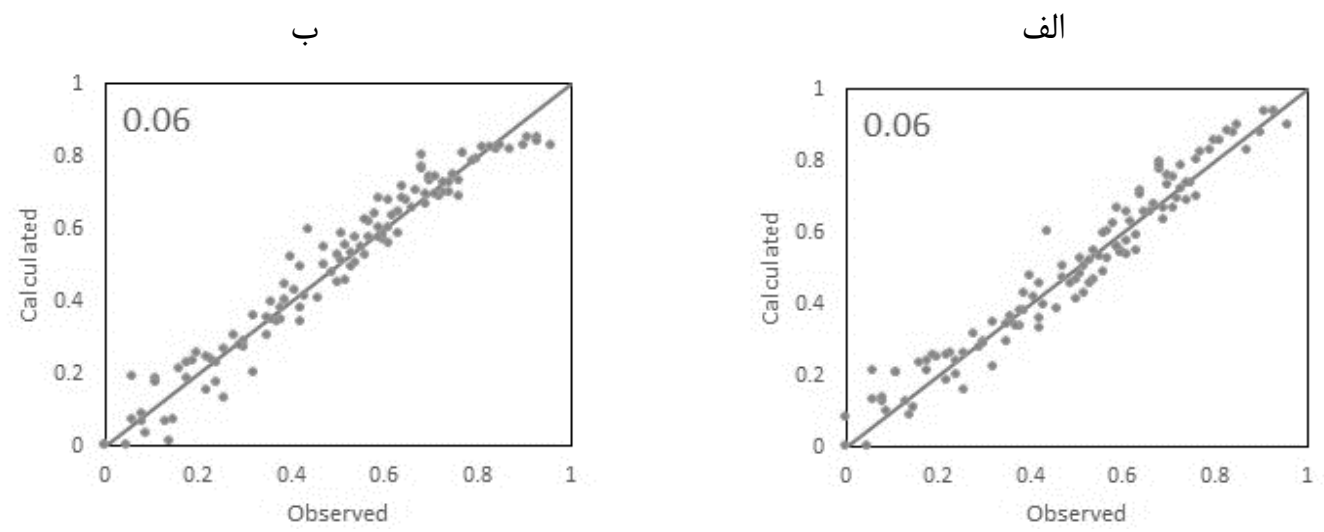

شكل f: نمودار ميزان حضور لكه سبز محاسبه شده بر حسب ميزان مشاهده شده با استفاده از روش

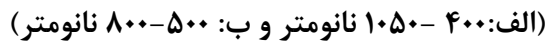



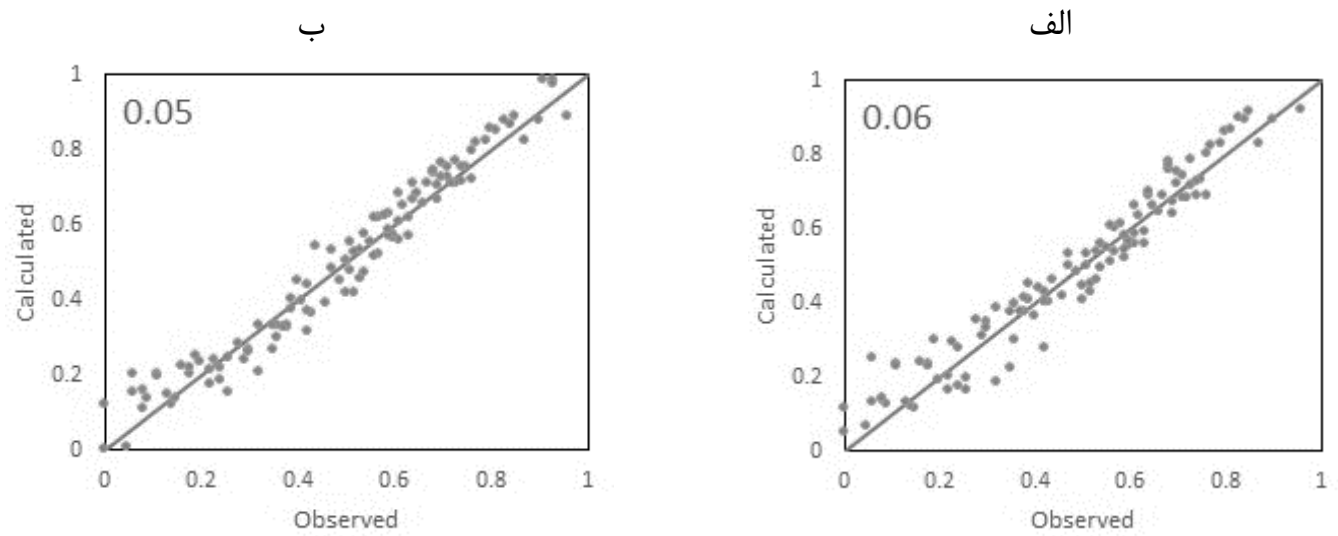

شكل ه: نمودار ميزان حضور لكه سبز محاسبه شده بر حسب ميزان مشاهده شده با استفاده از روش TC-3 Bit

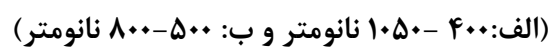

$\mathrm{RD}=100-\mathrm{PG}$

$\left(27^{\circ}<\mathrm{SAM} \leq 57^{\circ}\right)$

رابطه (YT)

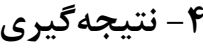

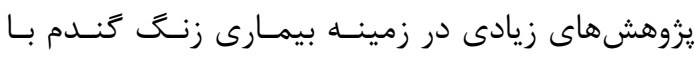

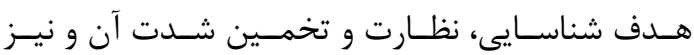

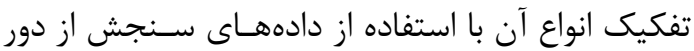

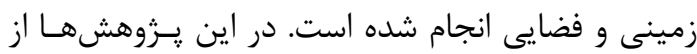

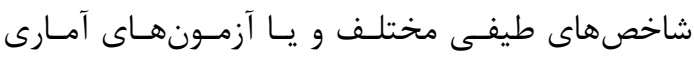

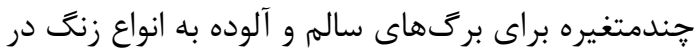

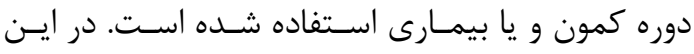

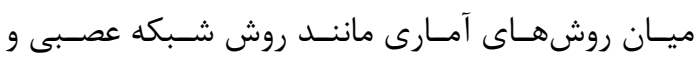

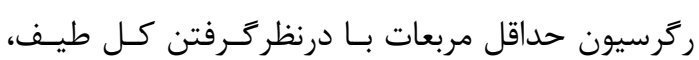

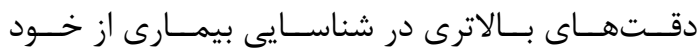
نشان دادهاند.

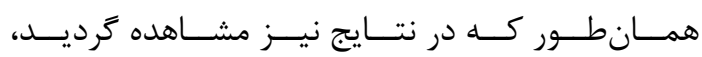
طول موجهاى · •ه تا · • م نانومتر نتايج بهترى نسـبت

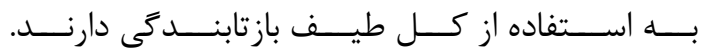

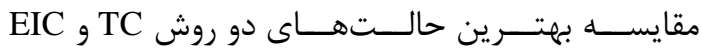
نشان مى دهد كه روش TC عملكرد بهتــرى نسـبت بــه روش EIC داشته كـه علـت آن عملكـرد سـخت مَيرانـه روشEIC در نسبت دادن عدد ا به هر بيت مـىباشـد.

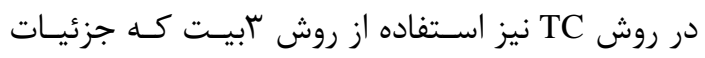

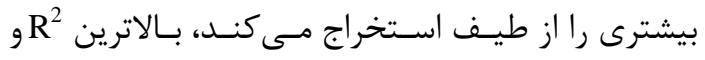
كمترين RMSE را براى دادههاى آزمون بههمــراه دارد.

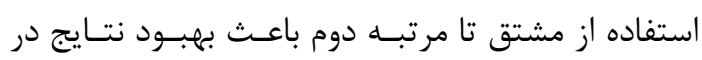

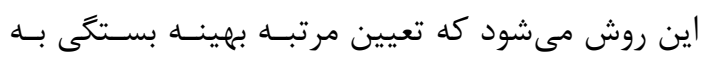
روش و باندهاى انتخابى دارد. بنابراين روش سوم با ســـ ريه

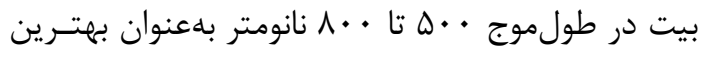

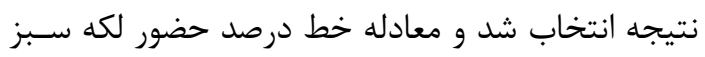
برحسب كسينوس زاويه شباهت (رابطه (Tr)) استخراج

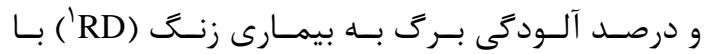

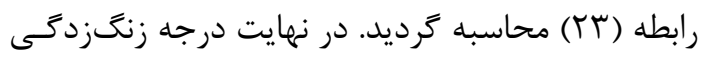
برى در أ سطح تعيين شد كه دقت كلى و ضريب كايـا

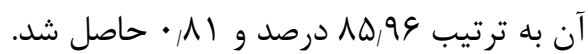

رابطه (Tr)

$\mathrm{PG}=(2.8328 \times(\mathrm{CS})-1.5199) \times 100$

${ }^{1}$ Rust Degree 


\begin{tabular}{|c|c|c|c|c|c|c|}
\hline & & \multicolumn{4}{|c|}{ جدول \&: ماتريس ابهام درجهبندى زنغ كندم در f fطح } & \multirow{3}{*}{ مجموع } \\
\hline & & \multicolumn{4}{|c|}{ مقدار محاسبه شده } & \\
\hline & & $\mathbf{0}<\mathbf{C R F}^{* *} \leq \mathbf{2 5}$ & $25<\mathrm{CRF} \leq 50$ & $50<\mathrm{CRF} \leq 75$ & $75<\mathrm{CRF} \leq 100$ & \\
\hline \multirow{5}{*}{ مشاهدهشار } & $0<\mathrm{ORF}^{*} \leq 25$ & 10 & 1 & . & . & 19 \\
\hline & $25<\mathrm{ORF} \leq 50$ & f & ऍ人 & $\Delta$ & - & iv \\
\hline & $50<\mathrm{ORF} \leq 75$ & - & r & מוt & r & r人 \\
\hline & $75<\mathrm{ORF} \leq 100$ & - & $\cdot$ & 1 & tr & 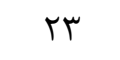 \\
\hline & مجموع & 19 & (1) & rq & ra & 114 \\
\hline
\end{tabular}

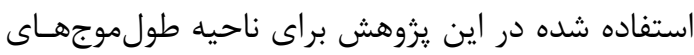

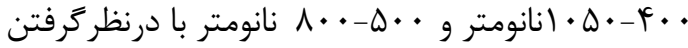

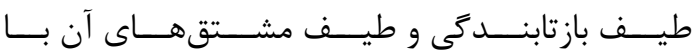

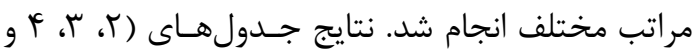

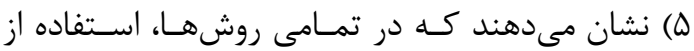

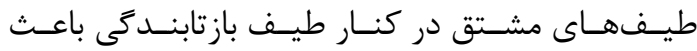

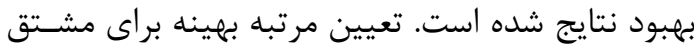

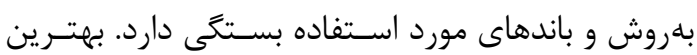

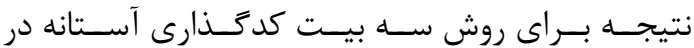

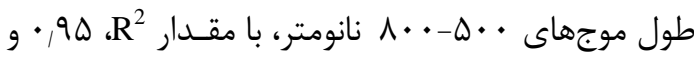
RMSE برابر ه • • • حاصل شد و دقت كلى درجهبنـدى مولى

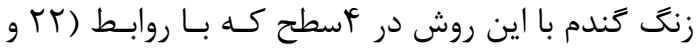

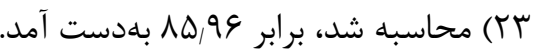

[1] S. Sankaran, A. Mishra, R. Ehsani, and C. Davis, "A review of advanced techniques for detecting plant diseases," Computers and Electronics in Agriculture, vol. 72, pp. 1-13, 2010.

[2] D. Ashourloo, "Developing an algorithme to estimate and detect wheat rust by field spectrometry", Ph.D Thesis, Geomatics Engineering Faculty, K.N.Toosi University of Technology, 2014.

[3] H. H. Muhammed, "Hyperspectral crop
اين يزوهش با هدف تخمين شدت زنتزدگى گنسدم در سطح برگ انجام شـد. ايـن روش مسى توانـد بـهـ عنـوان يايهاى براى استخراج اطلاعات از بازتابندگى اندازهخيرى شده توسط تصاوير سنجش از دورى استفاده شود[بr].

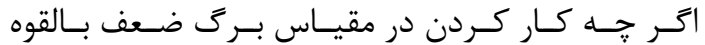
ناديده گرفتن تاثير ويزگگى هــاى سـاختارى اكوسـيتمى و بوته را دارد، با اين حال طيف بازتابندگى برگ يكى جـز

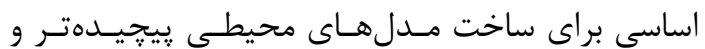

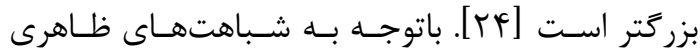
طيف هاى بازتابندكى و به منظــور اسـتفاده از اطلاعـات

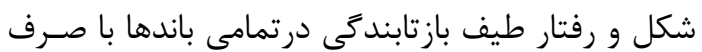
زمان كمتر و نيز بهدليل مزايـاى طيـف مشـتق و عـدم

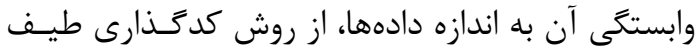

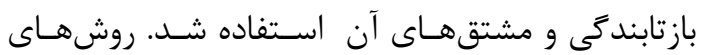

\section{مراجع}

reflectance data for characterising and estimating fungal disease severity in wheat," Biosystems Engineering, vol. 91, pp. 9-20, 2005.

[4] J. S. West, C. Bravo, R. Oberti, D. Lemaire, D. Moshou, and H. A. McCartney, "The potential of optical canopy measurement for targeted control of field crop diseases," Annual review of Phytopathology, vol. 41, pp. 593-614, 2003.

[5] M. D. Bolton, J. A. Kolmer, and D. F. 


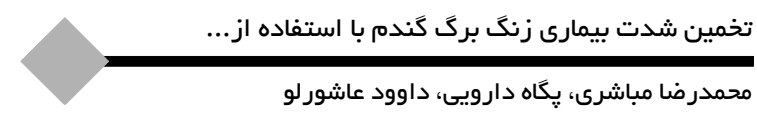

Garvin, "Wheat leaf rust caused by Puccinia triticina," Molecular plant pathology, vol. 9, pp. 563-575, 2008.

[6] D. Ashourloo, M. R. Mobasheri, and A. Huete, "Evaluating the effect of different wheat rust disease symptoms on vegetation indices using hyperspectral measurements," Remote Sensing, vol. 6, pp. 5107-5123, 2014.

[7] D. Ashourloo, M. R. Mobasheri, and A. Huete, "Developing two spectral disease indices for detection of wheat leaf rust (Pucciniatriticina)," Remote Sensing, vol. 6, pp. 4723-4740, 2014.

[8] J. Franke, G. Menz, E.-C. Oerke, and U. Rascher, "Comparison of multi-and hyperspectral imaging data of leaf rust infected wheat plants," in Remote Sensing, 2005, pp. 59761D-59761D-11.

[9] T. Mewes, B. Waske, J. Franke, and G. Menz, "Derivation of stress severities in wheat from hyperspectral data using support vector regression," in 2010 2nd Workshop on Hyperspectral Image and Signal Processing: Evolution in Remote Sensing, 2010, pp. 1-4.

[10]R. Devadas, D. Lamb, S. Simpfendorfer, and D. Backhouse, "Evaluating ten spectral vegetation indices for identifying rust infection in individual wheat leaves," Precision Agriculture, vol. 10, pp. 459-470, 2009.

[11]H. Wang, F. Qin, Q. Liu, L. Ruan, R. Wang, Z. Ma, et al., "Identification and disease index inversion of wheat stripe rust and wheat leaf rust based on hyperspectral data at canopy level," Journal of Spectroscopy, vol. 2015, 2015.

[12]D. Ashourloo, H. Aghighi, A. A. Matkan, M. R. Mobasheri, and A. M. Rad, "An Investigation Into Machine Learning Regression Techniques for the Leaf Rust Disease Detection Using Hyperspectral Measurement," IEEE Journal of Selected Topics in Applied Earth Observations and Remote Sensing, vol. 9, pp. 4344-4351, 2016.
[13] S. Naseri.Nasab, "Pixel-Based abundance estimation of minerals using the absolute minimum and maximum of reflectance curve", MSc Thesis, Geomatics Engineering Faculty, K.N.Toosi University of Technology, 2015.

[14]M. Ojaghloo, M. R. Mobasheri and Y. Rezaei, "Classification of hyperspectral images,Using derivative in the spectral space and coding methods," Iranian Journal of Remote Sensing and GIS, vol. 5, no. 1, pp. 13-28, 2013.

[15] A. S. Mazer, M. Martin, M. Lee, and J. E. Solomon, "Image processing software for imaging spectrometry data analysis," Remote Sensing of Environment, vol. 24, pp. 201-210, 1988.

[16] S. e. Qian, A. B. Hollinger, D. Williams, and D. Manak, "Fast three - dimensional data compression of hyperspectral imagery using vector quantization with spectral - feature based binary coding," Optical Engineering, vol. 35, pp. 3242-3249, 1996.

[17] C.-I. Chang, S. Chakravarty, H.-M. Chen, and Y.-C. Ouyang, "Spectral derivative feature coding for hyperspectral signature analysis," Pattern recognition, vol. 42, pp. 395-408, 2009.

[18]F. Tsai and W. D. Philpot, "A derivativeaided hyperspectral image analysis system for land-cover classification," IEEE Transactions on Geoscience and Remote Sensing, vol. 40, pp. 416-425, 2002.

[19] T. H. Demetriades-Shah, M. D. Steven, and J. A. Clark, "High resolution derivative spectra in remote sensing," Remote Sensing of Environment, vol. 33, pp. 55-64, 1990.

[20]W. D. Philpot, "The derivative ratio algorithm: avoiding atmospheric effects in remote sensing," IEEE Transactions on Geoscience and Remote Sensing, vol. 29, pp. 350-357, 1991.

[21] A. Martinez, A. Sawyer, J. Youmans and J. Buck, "Identification and Control of Leaf Rust of Wheat in Georgia," UGA Extension publications, Athens, Georgia, 2014. 
[22] R. S. Kim, "Spectral Matching using Bitmap Indices of Spectral Derivatives for the Analysis of Hyperspectral Imagery", MSc Thesis, The Ohio State University, 2011.

[23] K. L. Castro-Esau, G. A. Sánchez-Azofeifa, B. Rivard, S. J. Wright, and M. Quesada, "Variability in leaf optical properties of Mesoamerican trees and the potential for species classification," American Journal of Botany, vol. 93, pp. 517-530, 2006.
[24] A. Burkholder, T. A. Warner, M. Culp, and R. Landenberger, "Seasonal trends in separability of leaf reflectance spectra for Ailanthus altissima and four other tree species," Photogrammetric Engineering \& Remote Sensing, vol. 77, pp. 793-804, 2011. 


\title{
Wheat Leaf Rust Disease Severity Estimation Using Reflectance Spectrum Coding Methods
}

\author{
Mohamad Reza Mobasheri *1, Pegah Darouei², Davood Ashourloo ${ }^{3}$
}

1- Professor of Remote Sensing Laboratory, Khavaran Institute of Higher Education;

2- MS.c student of remote sensing, Faculty of Geomatics, K. N. Toosi University of Technology;

3- Assistant Professor, Remote Sensing Center, Shahid Beheshty University

\begin{abstract}
Using spectroradiometry and remote sensing techniques is an effective and rapid method in diagnosing vegetation diseases which enforced mostly by using spectral vegetation indices and statistical methods. The present study aimed to deploy encoding technique for the reflectance spectrum of the wheat leaves to assess the severity of the Rust disease. This is unlike to the spectral vegetation indices in which the shape of the spectrum, in all bands, independent from time and place is examined. A comprehensive laboratory spectroradiometry were used in the present study in which different stages of the development of the wheat rust stage were considered. The encoding methods were applied to the reflectance spectrum and its derivatives by the Equal Intervals Coding (EIC) and 1bit, 2bit and 3bit information and Threshold Coding (TC) methods for the 500-800 and 400-1050nm wavelength ranges. In this respect, the healthy green leaf code used as a reference. Then the similarity between any other leaf codes and the green leaf code were used to find the degree of the severity of the disease. Beside the reflectance spectrum, the progress of the disease on the leaf under observation were determined using a digital camera. The best result found to be for 3 bit- TC in the 500$800 \mathrm{~nm}$ wavelength region with R2 and RMSE of the order of 0.95 and 0.05 , respectively. Finally, the portion of the rust affected leaf was determined in four levels based on the green spot absence in which, the overall accuracy and Kappa coefficient were $85.96 \%$ and $0.81 \%$, respectively
\end{abstract}

Key words: Reflectance, Encoding, Similarity Angle, Wheat Rust, Derivation. 